\title{
Desigualdade e diferença: estrutura social, identidades e processo político a partir da teoria rawlsiana ${ }^{I}$
}

\author{
João Vinicius Marques \& Catarina Correa Von Sperling*
}

\begin{abstract}
Resumo: Este trabalho propõe-se a desenvolver um apanhado teórico valendo-se das contribuições de John Rawls e de algumas dimensões específicas de análise e de tratamento em sua teoria de justiça, recorrendo, para isso, a um estudo dos trabalhos do autor, entrecruzando com alguns dos desdobramentos teóricos repercutidos de sua teoria nos debates em filosofia e teoria política contemporâneas desenvolvidos por outros autores do campo. No âmbito em que seus princípios são estabelecidos, as bases da concepção de Rawls acerca da ordem social e de seus princípios de redistribuição são discutidas à luz dos paradigmas de justiça redistributivos e suas implicações críticas fundamentadas acerca da ordem nas sociedades liberais. Trata-se, para além das contribuições ralwsianas acerca de justiça, das discussões situadas no multiculturalismo, nas teorias de diferença e de reconhecimento e nas contribuições pós-estruturalistas acerca de uma democracia baseada na interação e no conflito político.
\end{abstract}

Palavras-chave: diferença, justiça, gênero, ordem social, desigualdade, identidade.

\section{Introdução}

O filósofo John Rawls reabriu, com uma contribuição expressiva, um campo de debates quase abandonado no momento em que lançou sua obra Uma teoria da justiça. Diminuído diante da vertente de estudos do positivismo jurídico (Kelsen, 2005) e da democracia liberal pluralista elitista (Schumpeter, 1961; DAHL, 2005), o espaço para as teorias normativas em justiça e democracia adquiriram novo fôlego com os escritos de John Rawls.

Na repercussão de seu trabalho, Uma teoria da justiça significou também um passo para a análise da sociedade moderna na perspectiva de fundamentos orientados à justiça social, instituída na garantia igual de direitos e baseada nos preceitos próprios da democracia que se desenvolvia no seio da sociedade liberal. Nesse sentido, os princípios rawlsianos avançavam não só na concepção de garantias e liberdades individuais, como estabeleciam também alternativas preliminares para

\footnotetext{
${ }^{1}$ Agradecemos os comentários preciosos e a revisão atenta dos(as) pareceristas anônimos(as) que nos renderam, durante a releitura de nosso trabalho, novas descobertas e importantes reconsiderações sobre o percurso filosófico rawlsiano.

* Graduandos em Ciência Política - UNB.
} 
a constituição de uma sociedade mais justa, pela distribuição de recursos e pela igualdade material entre os sujeitos. Empenhado na formulação de princípios de justiça dirigidos às instituições básicas da sociedade, Rawls propôs, à moda de um neocontratualismo kantiano, a definição de fundamentos morais específicos que se contrapunham não só às perspectivas utilitaristas e agregativas da maximização do bem-estar social da maioria como também às concepções morais difusas de justiça social que se colocavam na orientação dos valores e das possibilidades de garantia de direitos sociais. Valendo-se do resguardo às liberdades básicas iguais reservadas aos indivíduos e da sistematização de princípios básicos para a caracterização do que seria efetivamente justo para o funcionamento da ordem social, Uma teoria da justiça significou um marco para uma fundamentação sistemática dos princípios de justiça em um mundo de práticas e de concepções de bem tão diversificadas.

O critério que Rawls utiliza para conceber uma sociedade justa resulta da aplicação de procedimentos específicos. Os princípios enunciados por Rawls não se destinam à resposta a todos os problemas morais e à vida cotidiana em sociedade. As condições procedimentais por ele estabelecidas conduzem à escolha de princípios de justiça que regulam o que o autor intitula a estrutura básica da sociedade (RAWLS, 1999, p.84). Em seu escopo, a teoria dirige-se a um conjunto mais elementar de instituições sociais, ligadas à regulação da ordem e dos arranjos de cooperação da sociedade em seu momento inicial, voltado à delimitação de princípios mais básicos de justiça em que essas instituições fundamentais enquadrar-se-iam, estabelecendo as relações fundamentais de direitos e de deveres implicados aos sujeitos envolvidos nesse sistema de instituições principais e em suas regras.

$\mathrm{Na}$ perspectiva das formas integrativas da sociedade, geradoras de sistemas cooperativos nos termos da geração das relações de solidariedade na divisão do trabalho social de Durkheim (1978), nem todos os modelos de ordem social poderiam ser considerados razoavelmente justos, ainda que socialmente organizados, na medida em que os sujeitos viam-se constrangidos sob os códigos morais e sociais acima da possibilidade de suas escolhas. No contrato social rawlsiano, no entanto, a estrutura básica da sociedade estabelecer-se-ia sob princípios publicamente aceitos pelas partes desse contrato. 0 contrato social imaginado por Rawls situa-se em uma posição inicial hipotética e a-histórica. Nesse sentido, os sujeitos desse contrato chegariam a um consenso sobre os princípios de orientação dessa sociedade, delimitando sob que condições gerais as instituições mais importantes dessa sociedade 
estabeleceriam suas regras e manteriam a abertura à diversidade de concepções de bem e de formas de vida, no sentido em que seus princípios prezariam o não favorecimento a nenhum grupo, trajetória ou posição social em particular.

Nos princípios enunciados na teoria de John Rawls, as instituições básicas da sociedade estabelecem que o conjunto de obrigações, recursos e direitos são distribuídos pela estrutura básica da sociedade a seus sujeitos. A distribuição desses bens sociais e suas contrapartidas aceitas pelos sujeitos, com base nos princípios estabelecidos em um contrato, figuram como uma das questões fundamentais de justiça para Rawls. Tais bens, objetos da distribuição social por ele idealizada, são entendidos não estritamente em seu aspecto material, mas como o conjunto de recursos fundamentais a serem garantidos pelas instituições fundamentais da sociedade para o empreendimento dos planos e das expectativas variadas dos indivíduos nela inseridos. Compreendidos, em sentido amplo, como oportunidades, liberdades, disposições materiais, bases sociais do autorrespeito, dentre outros, esses recursos básicos deveriam estar ao alcance de todas as partes independentemente da posição social em que nasceram e de seus talentos naturais, em favor de condições de igualdade e de oportunidade a todos para a efetivação de seus planos e escolhas individuais.

Sob essa perspectiva, Rawls estabelece ainda uma segunda condição dirigida aos sujeitos situados em posições menos favoráveis na sociedade. Considerando as desigualdades de riqueza e poder e as condições naturais de que se favoreceriam alguns sujeitos em detrimento de outros na sociedade, o autor estabelece o princípio da diferença, no qual a distribuição social básica de recursos e bens entre os sujeitos justificar-se-ia apenas na medida em que se dirigissem à máxima melhoria possível dos sujeitos menos favorecidos socialmente ou das condições de todos (RAWLS, 1999, p. 6). Nesse sentido, a aplicação do princípio da diferença de Rawls demarcava não apenas a preocupação com segmentos desfavorecidos em sua trajetória e/ou pertencimento social no acesso a recursos fundamentais, como também associava uma perspectiva de justiça à constituição de uma sociedade equitativa sob o eixo em que direitos, deveres e bens sociais deveriam ser distribuídos entre os sujeitos.

Os princípios de justiça de Rawls, em sua resposta sistemática ao regimento das instituições sociais básicas, acabam por se afirmar como condições não apenas empenhadas nas dimensões equitativas da distribuição social, como também reconhecedoras de liberdades políticas e individuais básicas à sociedade liberal a que se 
dirige o autor. Em meio a um conjunto tão amplo de preocupações de justiça para a estrutura básica da sociedade, o procedimento a que recorre Rawls é uma ordem lexicográfica ${ }^{1}$ para hierarquizar seus princípios na sequência em que estes deveriam ser satisfeitos. Por fim, os princípios básicos rawlsianos resultam em que:

(i) cada pessoa deve ter um direito igual ao sistema mais extenso de iguais liberdades fundamentais que seja compatível com um sistema similar de liberdades para as outras pessoas e (ii) as desigualdades sociais e econômicas devem estar dispostas de tal modo que tanto (a) se possa razoavelmente esperar que se estabeleçam em benefício de todos como (b) estejam vinculadas a cargos e posições acessíveis a todos (RAWLS, 2008, p. 73).

O impacto, causado pela relativa novidade com que soaram as preocupações de Rawls em seu primeiro trabalho, recebeu ecos e influenciou muitas outras contribuições posteriores até os dias atuais; as contribuições de Rawls que se seguiram a ele permanecem como fonte de inspiração e de questionamento para o debate contemporâneo.

Este trabalho se propõe a desenvolver um pequeno apanhado teórico valendo-se das contribuições de John Rawls (1921-2002) e de algumas de suas dimensões específicas de análise e de tratamento em sua teoria de justiça, recorrendo, para isso, a um estudo de A Theory of justice (1999) e de Political liberalism (1996), entrecruzando com alguns dos desdobramentos teóricos repercutidos de sua teoria nos debates em filosofia e teoria política contemporâneas desenvolvidos por outras autoras e outros autores do campo. Mais que pensar as contribuições rawlsianas pela sua própria obra, este trabalho pretende partir de Rawls no sentido em que seus postulados incitaram novas reflexões sobre a justiça e o processo político nas sociedades liberais, para além até mesmo dos limites e pretensões teóricas em que se constituíram a teoria de justiça rawlsiana.

Nesse sentido, o trabalho desenvolve-se a partir de três aspectos fundamentais da contribuição de Rawls na repercussão dos debates nas teorias de justiça e, principalmente, no processo político recente: (i) na concepção de Rawls acerca da ordenação da estrutura básica da sociedade e da aplicabilidade de seus princípios nas instituições sociais; (ii) no tratamento de Rawls reservado à acomodação da

\footnotetext{
${ }^{1}$ Sobre a ordem lexicográfica adotada por Rawls, cf. Rawls (1999, p. 42-43 e 61-62); sobre o conceito rawlsiano de pure procedural justice, cf. Rawls (1999, p. 85-87).
} 
diversidade de formas de vida e suas implicações na compreensão da constituição de identidades e de diferença nas sociedades contemporâneas; (iii) no desenvolvimento das contribuições ralwsianas acerca de justiça sobre o desenvolvimento do processo político nas sociedades contemporâneas e suas implicações para o funcionamento da democracia e da dinâmica do processo político nas sociedades atuais.

\section{Os véus de Rawls: a posição inicial e os caminhos da justiça rawlsiana nas instituições sociais}

Na perspectiva de Rawls, não era desejável que seus princípios de justiça se traçassem em benefício de sujeitos bem estabelecidos na sociedade. Princípios de justiça criados sob as margens e as concepções de bem de grupos de indivíduos dotados de talentos ou posições de poder e riqueza na estrutura social deixariam de considerar as condições e as necessidades básicas de sujeitos cuja situação nesta sociedade não seria a mesma. Da mesma forma, o recurso a que recorre Rawls se constitui a partir de uma posição dessituada dos interesses e valores incorporados pelos sujeitos relativos à sua posição na sociedade e de forma que os princípios acordados significassem também a constância de relações duráveis de um contrato que regesse a estrutura básica da sociedade dele proveniente, de modo que seus princípios se antecipassem ao seu objeto de aplicação. É neste contexto de preocupações que Rawls estabelece a posição original desse contrato. Na teoria rawlsiana, as pessoas aceitam um princípio igual, que é determinado independentemente da posição social de cada indivíduo e de seus objetivos específicos (RAWLS, 1999, p. 31).

A posição original é um espaço de determinação da concepção de justiça, no qual todas as pessoas são racionais e conversam a partir de um juízo ponderado dos sujeitos, com a razão mais ou menos livre de instabilidades ou contingências emocionais sobre seus juízos, em que se escolhem os princípios de justiça, orientados em uma razão moral mutuamente desinteressada entre as partes. Na posição original, as contingências que definem as diferentes condições sociais atribuídas a determinadas trajetórias são invisíveis àqueles que participam, uma vez que o debate deve ser pautado puramente por princípios morais, e não por aqueles argumentos que surjam em função da própria posição social que cada indivíduo ocupa. 0 desconhecimento acerca das contingências e características, posição social, econômica e histórica que cada um preenche na sociedade é o que garante que os princípios advindos de tal espaço são legítimos na medida em que sua moralidade é idealmente neutra, e 
suas condições específicas idealmente desconhecidas: os sujeitos morais da posição de Rawls são envolvidos no véu da ignorância² .

$\mathrm{Na}$ orientação de sua concepção de justiça, a neutralidade se estabelece como recurso filosófico fundamental de Rawls para o reconhecimento público de seus princípios, nos quais os sujeitos da posição original aceitariam tais princípios para a regulação das instituições básicas da sociedade deslocadas de seus valores socialmente situados e de suas experiências e interesses privados. A neutralidade contida no véu da ignorância, proposto pelo autor, definiria as condições de estabelecimento de seus princípios de justiça, em que seus sujeitos morais idealmente neutros aceitariam publicamente o sistema de regras da estrutura básica da sociedade. Por outro lado, os princípios de justiça de Rawls fundamentados na neutralidade não satisfazem uma dimensão importante das questões de justiça, em que a atenção às especificidades dos sujeitos sociais e a existência de instituições caracterizadas pela esfera privada manifestariam obstáculos e formas de injustiça para além da aceitação e a regulação pública dos sujeitos morais neutros ou imparciais. Fora do escopo e das pretensões teóricas de John Rawls, o âmbito privado da vida social dos sujeitos morais e algumas instituições socialmente relevantes dessa esfera parecem ter sido deixados de lado com o véu da ignorância.

Segundo sua própria teoria, seu objeto de análise são as diferentes instituições sociais importantes que constituem a estrutura básica da sociedade. 0 que parece não ser colocado substantivamente em questão, no entanto, é a relação entre as instituições e suas esferas internas de reprodução e suas possibilidades de aplicação dos princípios de justiça em consonância com os princípios de justiça regentes da estrutura social básica e seu sistema de regras públicas. No seio dessas instituições que alimentariam o ordenamento social mais abrangente, o mercado e a família monogâmica, por exemplo, estabelecer-se-iam sob concentrações relevantes de poder, mas às margens do alcance dos princípios de justiça de que se vale Rawls por se situarem em dimensões específicas e ocultas da esfera privada, ao resguardo da

\footnotetext{
${ }^{2} \mathrm{O}$ véu da ignorância é um recurso filosófico fundamental da posição original ao qual recorre Rawls para construir a maneira como os princípios da justiça são estabelecidos, na medida em que os sujeitos, sob o véu, estão livres das suas contingências sociais e pensam a sociedade considerando a possibilidade de ocupar qualquer posição social que possa existir e protegendo os próprios princípios de justiça das arbitrariedades morais. Sobre o véu da ignorância, suas relações com a tradição filosófica kantiana e a preocupação de Rawls com a correção da arbitrariedade, ver Rawls (1999, p. 136-142).
} 
publicidade dos princípios rawlsianos. Tal justiça, neste sentido, não permearia as disposições internas de poder dessas instituições, sendo a estrutura básica da sociedade um sistema abstrato e fechado dentro do qual a justiça é concebida. Pensar a aplicabilidade dos princípios de justiça de Rawls no regimento interno das instituições básicas da sociedade e nos processos da esfera privada de seus sujeitos morais constitui, possivelmente, uma preocupação importante na ampliação do próprio escopo e do potencial crítico de sua própria teoria de justiça.

É neste sentido que Okin apresenta sua crítica em Justice, gender, and the family (1989), sob o entendimento de que as relações estruturantes da família, uma das instituições básicas da teoria rawlsiana, configuram uma concentração de poder definidora sobre relações sociais específicas - principalmente no tocante às relações de gênero. Embora considere a teoria de Rawls promissora para a resolução das desigualdades de gênero, Okin se depara com um problema na consideração da família como parte da estrutura básica da sociedade, ora presente, ora ausente nas preocupações de justiça de Rawls, sugerindo, ainda, que gênero deve ser um fator incluído sob o véu da ignorância. A permeabilidade ambígua dos princípios de justiça de Rawls sobre a família mantém uma instituição na qual os padrões de injustiça são reproduzidos quase à revelia da moral justa presente na sociedade e em suas instituições básicas. A representação da família da perspectiva de Rawls é contrastada pela visão de Okin na medida em que as relações de desigualdade e de cerceamento internas à esfera familiar estariam escondidas sob o plano das relações de intimidade e de proteção subsumidas à concepção de família de Rawls - possível somente a uma parte dos que a constituem: segurança e intimidade ao elemento masculino em que a mesma esfera privada significaria também o espaço de opressão e de injustiça para muitas mulheres. Na perspectiva de Okin, a família seria uma das instituições fundamentais as quais os filtros dos princípios de justiça de Rawls deveriam ser aplicados, apropriando-se das fundamentações de neutralidade estabelecidas na posição original para conceber dimensões nas quais o trabalho doméstico e a conexão entre aspectos do público e do privado permeariam espaços e atividades que restringiriam a participação da mulher à esfera doméstica reafirmando o favorecimento aos homens, expressos na instituição da vulnerabilidade da mulher no casamento, por exemplo.

Para além da importância que Rawls confere à família como instituição social básica, Okin percebe as desigualdades entre gêneros no seio familiar como os 
ilustres ausentes nas preocupações teóricas de Rawls sob as quais nem mesmo os aprendizados morais constituídos na família poderiam disseminar os princípios de justiça fundamentados na teoria rawlsiana ${ }^{3}$. A família, grande força interna à difusão dos preceitos morais de justiça para Rawls, é possuidora de assimetrias nas quais a justiça como equidade não poderia ser reproduzida a partir das desigualdades existentes na esfera familiar - não até que os princípios estabelecidos por Rawls tomassem a orientação prática das disposições internas das relações entre homens e mulheres na esfera doméstica, o que defende Okin (1989).

Em consonância com a forma predominante de liberalismo, Rawls preserva uma fronteira constituída entre o público e o privado em sua concepção de justiça social que é estabelecida na problematização das questões sociais compartilhadas e socialmente reconhecidas - e, de modo genérico, públicas - em contraposição a uma desconsideração das disposições injustas escondidas sob o campo livre das relações da privacidade e da esfera individualizada. Na medida em que o público separa-se do privado em suas atribuições e esferas de intervenção, a acessibilidade das instituições reguladoras e garantidoras da justiça é reduzida ou inexistente sobre a esfera privada, de forma que a família permanece internamente imune e sob um "novo véu" obscuro até mesmo ao próprio Rawls: o que separa o pessoal do público, da esfera da regulação, da intervenção ou da justiça pública; o que separa, enfim, o privado do campo de intervenções da justiça e do político. No sentido da crítica da teoria política feminista às dimensões políticas resguardadas e persistentes na esfera privada, Okin afirma que a distinção liberal entre o público e o privado é ideológica, pois apresenta a sociedade a partir de uma perspectiva masculina tradicional baseada em naturezas e papéis sociais naturalizados na distinção de gênero:

[...] poder e práticas políticas e econômicas [que] são estreitamente relacionados às estruturas e práticas da esfera doméstica, expuseram o quanto a dicotomia entre público e doméstico, também reificada e exagerada pela teoria liberal, serve igualmente a funções ideológicas (OKIN, 2008, p. 312).

\footnotetext{
${ }^{3}$ Sobre a importância atribuída por Rawls à família na disseminação dos princípios de justiça da conformação moral dos sujeitos, ver Rawls (1999, p. 453-467).
} 
Em um sentido mais amplo e da concreticidade das diferentes posições sociais ocupadas pelos sujeitos, o significado subjacente à valorização da neutralidade de Rawls em sua concepção de justiça estabelece pontos de invisibilidade à percepção das distinções não apenas de gênero, mas às perspectivas culturais de modo geral, na medida em que o valor da neutralidade não só afasta dos sujeitos morais rawlsianos suas dimensões de interesse socialmente situados dos princípios de justiça estabelecidos na posição original, como também parece considerar pouco relevantes as diferenças culturais e perspectivas identitárias em suas condições definidoras e estruturantes das visões de bem e das concepções morais de justiça dos contratantes idealizados por Rawls (AvRITZER, 2000). Para Rawls, estabelecer e fundamentar os princípios de justiça à parte das condições particulares, ignorando os eventuais vieses práticos das diferenças dos sujeitos para sua definição, parece ser bem mais atrativo em suas pretensões filosóficas, no sentido em que sua teoria não pretende discorrer sobre as questões práticas e cotidianas de justiça, na medida em que se dirige à estrutura básica (e abstrata) da sociedade. Não obstante, os aspectos de sua concepção de justiça defrontam-se com obstáculos consideráveis, do ponto de vista em que seus princípios pretendem-se aplicáveis em sociedades complexas e culturalmente diversificadas ${ }^{4}$. Em uma análise das condições em que coloca a proposta de Rawls, a imparcialidade parece ser também uma alternativa para supor contempladas as necessidades de sujeitos sob condições universais, mantendo à parte as dimensões específicas em que se estabelecem necessidades básicas diferentes entre os sujeitos de uma sociedade complexa e culturalmente diversificada. Contemplar a diversidade em suas especificidades parece fugir às preocupações de Rawls, mas constitui uma das dimensões fundamentais na concepção da justiça em sociedades de grupos de pessoas com trajetórias histórico-culturais e noções de pertencimento social tão heterogêneos entre si. Em Uma teoria da justiça, parte das preocupações de Rawls relativas às diferenças sociais parece estar mais associada a uma dimensão mais inclinada à justiça equitativa de distribuição de bens ${ }^{5}$.

\footnotetext{
${ }^{4}$ Sobre o debate acerca das sociedades complexas e culturalmente diversificadas em Rawls, ver mais adiante a leitura aqui desenvolvida sobre a obra Political liberalism (1996).

${ }^{5}$ Sobre a distribuição dos sociais considerados por Rawls, ver a introdução deste trabalho.
} 
Rawls emprega o princípio da diferença para condicionar a utilização dos talentos e recursos disponíveis na natureza em certos aspectos do bem comum. Nesse sentido, os talentos naturais a alguns sujeitos e a disposição escassa ou não de alguns recursos materiais no ambiente não são justos nem injustos, mas fatos ou elementos dados com que a sociedade, suas instituições e regras devem estabelecer a devida distribuição desses elementos em benefício de todos (RAWLS, 1999, p. 102), devendo acomodá-la dentro das possibilidades de estabelecimento de seus princípios de justiça. Na intenção de Rawls em extirpar as condições arbitrárias das disposições sociais herdadas de sua concepção de uma sociedade justa, tal sociedade aproximar-se-ia ao máximo de uma sociedade igualitária em oportunidades e bens a todos os indivíduos, independentemente da posição relativa dos sujeitos na estrutura social, em suas disposições de herança e na posse de talentos naturais específicos variados. A diferença, ou, melhor, a desigualdade de alguns indivíduos em relação a outros justificar-se-ia apenas na capacidade destes de tornar melhor a situação de outros sujeitos situados em condições menos favoráveis na estrutura social. Desse modo, para Rawls, em sua perspectiva igualitária de justiça, as diferenças consideradas em seu trabalho orientam-se à compreensão de desigualdades, no entendimento de que os aspectos distintivos sociais e distributivos entre os sujeitos seriam elementos transitórios e modificáveis na construção de ordem social moralmente justa, independentemente das constituições socialmente distintivas da identidade, dos costumes e do pertencimento social dos indivíduos, questões essas relativas à diferença, não necessariamente ligadas às questões de disponibilidade equitativa - ou da referida desigualdade - de recursos.

Do que Rawls parece aproximar-se, sua concepção de justiça acaba por desconsiderar aspectos constitutivos das diversas formas de vida e de elementos específicos necessários à garantia de liberdades iguais para determinados segmentos na sociedade caracterizados exatamente por sua dimensão de heterogeneidade, para os quais os princípios estipulados por Rawls seriam insuficientes do ponto de vista prático para a garantia de justiça a estes grupos. Na perspectiva de Young (1990), o tratamento reservado aos objetos de justiça como bens a serem possuídos e socialmente redistribuídos ignoraria ainda uma dimensão importante das relações sociais como processos. Nesse sentido, as situações de poder e injustiça estariam implicadas ainda em contextos institucionais e processos de tomada de decisão em que a própria estrutura social, em seus atributos simbólicos e em suas formas diver- 
sas de influência sobre as relações sociais, não permitiriam que uma concepção mais ampla de justiça fosse possível a partir de uma dimensão puramente redistributiva ${ }^{6}$, seja de bens, direitos, ou poderes. A perspectiva de Young (1990) aponta para uma noção na qual a justiça não seria alcançável apenas da redistribuição de recursos ou de oportunidades, mas de uma reestruturação das disposições de poder existentes entre grupos e segmentos socioculturais diversificados, na qual as dinâmicas de poder e das diferenças, em sentido mais amplo, adquirem o status de uma variável importante na idealização de valores de justiça social.

\section{Carne e ossos: a pluralidade em Rawls e o processo político na sociedade contemporânea}

Em Uma teoria da justiça, Rawls preocupa-se com o estabelecimento de uma sociedade bem ordenada sob os princípios de justiça enunciados em seu trabalho, os quais são dirigidos à estrutura básica da sociedade e deveriam garantir o estabelecimento de um sistema de instituições básicas justas que mantivessem a ordem e a estabilidade dessa sociedade a partir da cooperação de seus cidadãos, na medida em que aceitariam tais princípios regentes e as regras publicamente acordadas que seriam provenientes desses princípios (RAWLS, 1999, p. 454-455). Aceitos esses princípios pelas partes de sua posição original hipotética, a justiça concebida por Rawls conduziria ainda a uma ordem estável e a que os cidadãos sentir-se-iam motivados à obediência a seus princípios e à cooperação social em seu próprio benefício e no reconhecimento da igualdade e da liberdade dos demais cidadãos dessa sociedade. Na medida em que os sujeitos rawlsianos colocavam-se à aceitação de uma concepção pública de justiça, reconhecida em consonância princípios aceitos e formulados a partir de suas próprias condições na posição original proposta por Rawls, a estrutura básica da sociedade permitiria a liberdade aos seus indivíduos para buscar seus próprios fins e assegurar-lhes, igualmente, os recursos necessários para que suas iniciativas fossem alcançadas em favor também da própria sociedade e da manutenção da cooperação social.

\footnotetext{
${ }^{6}$ Um dos grandes debates na Teoria Política Contemporânea diz respeito à suposta transitoriedade do paradigma de justiça redistributiva para perspectivas de reconhecimento. Embora fundamental para a melhor compreensão dos temas e conceitos aqui desenvolvidos, foge ao escopo deste trabalho o esclarecimento ou a delimitação deste debate. Para ver mais, Fraser e Honneth (2003), Young (1990, p. 15-38), Fraser (1997), Cohen e Arato (1997).
} 
Em um trabalho posterior - Political liberalism (1996) -, Rawls propõe-se a uma revisão das condições da estabilidade dessa sociedade sob seus princípios de justiça, atribuindo especial consideração a outro elemento das sociedades modernas e democráticas, a saber, a existência do pluralismo moral. Tomando em conta a diversidade cultural das sociedades liberais modernas, Rawls tenta desenvolver os princípios ou condições sob as quais seria possível o estabelecimento de uma sociedade justa e bem ordenada em meio ao fato de uma multiplicidade de doutrinas morais, filosóficas e religiosas conflituosas e contrapostas entre si (RAWLS, 1996, p. xix-xx). Nesse sentido, a proposta de Rawls dirige-se à constituição de valores morais e democráticos que permitissem o exercício livre dessa pluralidade ao mesmo tempo em que tornasse possível a estabilidade e a manutenção da cooperação necessária entre os cidadãos, não obstante suas dissidências de perspectivas diversas.

Para Rawls, uma das condições para a existência desejável dessas doutrinas ou perspectivas morais variadas é sua razoabilidade, a saber, à medida em que essas doutrinas e perspectivas seriam tolerantes à existência de outras perspectivas e aos princípios e bases de valores reconhecidamente públicos, apresentados não apenas nos princípios de justiça como também nos valores de liberdade política e no conjunto de direitos e contrapartidas reservadas aos cidadãos com a sociedade, de modo geral. Do ponto de vista em que Rawls propõe-se a delinear os princípios políticos que permitiriam o resguardo desses valores de liberdade, o autor estabelece ainda que as condições de formação dos princípios de justiça política deveriam ser também constituídas sem que privilegiassem ou favorecessem nenhuma doutrina moral ou filosófica em particular (Rawls, 1996, p. 13). Na perspectiva de John Rawls, o liberalismo político efetivamente aberto à multiplicidade dessas doutrinas morais razoáveis deveria fazer-se, mais uma vez, a partir da neutralidade.

No campo em que se inserem as teorizações de justiça de Rawls, sua contribuição é inegável. No enfoque atribuído em suas fundamentações morais assumido em Uma teoria da justiça, Rawls estabelece em que medida seus princípios de justiça na sociedade justificar-se-iam independentemente das práticas e dos valores sociais diversos na sociedade, permitindo um nível de abstração e, ao mesmo tempo, de proposição normativa para a regulação das instituições sociais que fica ainda à frente de iniciativas partidas em sentido semelhante. É na medida em que sua abstração distancia-se de confrontações mais concretas, a partir da posição original e de sua idealização do véu da ignorância, que Rawls consegue um nível de normatização es- 
truturante das disposições vigentes que permite atravessar as barreiras e injustiças da realidade social, permitindo, ao mesmo tempo, que seu principialismo abstrato acomode-se aos valores e às disposições de uma sociedade liberal com necessidades de um ordenamento menos desigual, mas ainda assim aberta à pluralidade e à diversidade de formas de vida.

Em Political liberalism, Rawls mantém seu recurso ao definir, em linhas gerais, princípios para pensar a justiça em instituições mais ou menos abstratas. Não obstante, a nova preocupação a que o autor dirige-se sugere um deslocamento para um âmbito mais concreto e próximo da dinâmica social existente, no sentido em que tais princípios, para a tolerância e a estabilidade da sociedade moderna, deparam-se com a necessidade de reconhecer e conciliar alguns de seus conflitos e diversidades conflituosas da realidade. 0 objeto das preocupações de justiça de Rawls, dirigida à liberdade dos sujeitos no exercício dessas doutrinas morais razoáveis, situa-se na constituição de uma ordem ou constituição democrática, no sentido em que os dispositivos constitucionais dessa democracia garantissem, em termos gerais, o conjunto de liberdades dessas doutrinas, e à medida em que essas doutrinas fossem aceitáveis à constituição dessa sociedade livre e democrática.

Os princípios desenvolvidos por Rawls em Political liberalism para definir as condições de aceitabilidade das doutrinas morais existentes socialmente deveriam obedecer às condições de tolerância à pluralidade e, ao mesmo tempo, serem coerentes ou, ao menos, não influírem sob as condições do acordo social mais amplo relativo à cooperação e aos princípios de justiça apresentados pelo autor em Uma teoria da justiça. No campo em que esses princípios fossem estabelecidos, a tônica de sua formulação deveria ser situada na neutralidade e na condição em que esses princípios fossem também amplamente aceitos a partir das ponderações dos sujeitos morais dessa sociedade (RAWLS, 1996, p. 37). Os sujeitos ou pessoas morais concebidas por Rawls, nesse contexto, aceitariam esses princípios a partir de seus juízos ponderados, resultando em uma condição na qual, em favor da razoabilidade e do estabelecimento de uma sociedade democrática e estável, chegariam ao que o autor chama de consenso sobreposto (overlapping consensus) (Rawls, 1996, p. 39), estágio de aceitação das condições e princípios alcançados não necessariamente a partir de uma deliberação ou de um estágio de excepcionalidade na definição dos princípios - como o que se estabelece na posição original de Rawls para os princípios de Uma teoria da justiça -, mas em que os sujeitos, considerados razoáveis e de juízos racionais ponderados, chegariam à constatação da razoabilidade destes princípios. 
No novo empreendimento filosófico de John Rawls, sua iniciativa parece tentar dar conta de um conjunto de novas preocupações e adaptações de seus antigos princípios com ferramentas, conceitos e arcabouços já utilizados em sua Uma teoria da justiça. Se, nesse sentido, suas considerações estabelecem continuidade e certa coerência com o corpo mais amplo de sua teoria e suas preocupações anteriores, os conflitos relativos ao seu novo objeto e certos aspectos relativos às pessoas morais centrais concebidas por Rawls, em Political liberalism, geram alguns tensionamentos relevantes em sua argumentação para tratar com questões da aceitabilidade dos princípios por esses "novos" sujeitos, situados em condições mais concretas. Na perspectiva de Jürgen Habermas, um dos filósofos sociais de extensa interlocução de simpatia com boa parte dos propósitos e das perspectivas ideais de neutralidade e racionalidade de John Rawls, a guinada argumentativa de Rawls no campo da fundamentação de seus princípios de justiça seguiu-se não sem grandes constrangimentos. Segundo Habermas (2002), a nova preocupação de Rawls orientada na justificação de como seus princípios de justiça seriam razoáveis para a aceitação de sujeitos sociais (e reais) de concepções de bem tão diferentes entre si acaba por estabelecer uma relação de transitoriedade do campo da justificação moral, predominante em sua obra anterior, para um conjunto de necessidades de fundamentação de sua aceitabilidade em sociedades complexas, como se o âmbito de justificação de seus princípios, como moralmente corretos, assumissem, em seu novo trabalho, as expectativas de justificação de sua aceitação possível. No campo em que Rawls recorre ao consenso sobreposto para justificar a aceitabilidade dos princípios liberais propostos, uma parte importante relativa aos processos de deliberação e barganha na constituição das escolhas e formação de consensos entre esses sujeitos fica às margens de suas considerações ideais acerca da aceitação de seus princípios.

Baseado na ideia do consenso sobreposto, Rawls imagina que a razoabilidade dos sujeitos morais da sociedade levaria à aceitação de seus princípios de justiça sem que fosse necessário qualquer processo de barganha ou de adaptação das escolhas morais desses sujeitos. Para Habermas (2002), Rawls ignoraria a necessidade dos processos de deliberação envolvidos na aceitabilidade ou na generalização moral destes princípios, preocupando-se em demasia com as instituições e conceitos fundamentais que orientam a construção do consenso:

é preciso que o conceito central de pessoa, sobre o qual a teoria se apoia, seja tão neutro que possa ser aceito a partir das perspectivas interpretativas de diferentes visões de mundo. [...] Diante do fórum do uso público da razão, a teoria em seu todo precisa 
ser exposta à crítica dos cidadãos; trata-se aí não mais de cidadãos fictícios de uma sociedade justa, sobre os quais se pode emitir enunciados no interior da teoria, mas sim de cidadãos de carne e osso; a teoria precisa manter em aberto o término de um teste como esse (HABERMAS, 2002, p. 75).

Em um sentido mais amplo, as críticas dirigidas ao desenvolvimento das considerações e argumentos de Rawls parecem remeter a recursos e abstrações do autor já presentes mesmo em Uma teoria da justiça. Para além das possíveis complicações internas presentes no trabalho de John Rawls, a que se seguem inúmeras réplicas e controvérsias ${ }^{7}$, os caminhos tomados em Political liberalism parecem apresentar limitações importantes a serem consideradas, na medida em que os processos e dinâmicas sociais existentes, fora das pretensões filosóficas de Rawls em seu trabalho, deixaram também parte significativa dos desdobramentos da conflituosidade e da diversidade presente entre perspectivas morais, culturais e filosóficas existentes na sociedade. Dentro de outras perspectivas e abordagens da justiça e do processo político na contemporaneidade, as preocupações de Rawls são recolocadas e vistas sob outro conjunto de aspectos relevantes.

Em Political liberalism, Rawls estabelece uma preocupação situada em princípios que antecedem um conjunto de regras para a regulação da convivência de perspectivas de mundo diversas, em que parecem manifestar-se a partir de suas colocações acerca das condições de razoabilidade das doutrinas morais e das condições estabelecidas em seu consenso sobreposto. Em última instância, sua preocupação em conciliar esses princípios de convivência com um conjunto de instituições básicas e públicas da sociedade parece gerar um conflito relativo à regulação pública e democrática de direitos e liberdades de manifestação e exercício de grupos, minorias, e individualidades presentes na ordem pública, questão parte do amplo conjunto de implicações relativas ao público e ao privado, já esboçadas em partes anteriores deste trabalho. Na proposta de Rawls, os princípios publicamente aceitos à diversidade seriam satisfeitos, constituídos sob critérios neutros, e satisfatórios à totalidade das pessoas e suas concepções morais razoáveis variadas na medida em que não contemplava nenhuma posição em particular. 0 extremo oposto da imposição de uma doutrina moral, filosófica ou religiosa pelo Estado seria condição injusta

\footnotetext{
${ }^{7}$ Para ver debates anteriores, cf. Young (1990), Okin (1989), Mouffe, (1985, 2000, 2006) e Habermas (2002).
} 
imponderável a uma perspectiva pluralista de justiça; não obstante, a neutralidade e o principialismo de Rawls para uma ordem constitucional democrática parece carecer da consideração de elementos de conflito e poder inerentes à própria dinâmica de interação dos grupos e diversidade existentes na sociedade, a que Rawls parece desconsiderar no escopo de sua proposta de liberalismo político a partir de sua instância filosófica do consenso sobreposto.

É neste sentido sobre o qual Habermas aponta que Rawls acaba por escamotear a conflituosidade existente sobre um consenso sobreposto em que não há preocupação com o processo concreto de barganha e deliberação; as dimensões de conflito e de luta por reconhecimento (HonNETH, 2003) na sociedade e no interior dessas estruturas são esquecidas do processo político. Um pouco mais de atenção aos argumentos de Rawls, à dinâmica subjacente à constituição das doutrinas morais e dos conflitos por reconhecimento, abririam possibilidades para a compreensão de abismos existentes entre a aceitação moral e a imposição da exclusão a partir da sobreposição de ordens simbólicas e fundamentos hegemônicos sob perspectivas e formas de vida comumente representadas como ideológicas, irracionais ou, simplesmente, dissidentes.

O que se observa é que ainda que o consenso construído a partir da sobreposição dos juízos das pessoas morais de diversas doutrinas morais e filosóficas seja aceitável do ponto de vista filosófico, o principialismo abstrato rawlsiano ignora, na concretude das lutas políticas, a lógica que rege os espaços públicos, sendo subsídio para pensar uma ordem pretensamente neutra e que exclui grupos que não se façam visíveis ou que sejam marginalizados e invisibilizados. Nesse sentido, a própria razoabilidade é definida politicamente e não é universalmente razoável e racional, conforme Rawls propõe.

Para Mouffe (2000), na medida em que o público elimina o poder sob a pretensão de obter um consenso, o que se produz é uma dimensão que não reconhece o antagonismo que decorre do pluralismo de valores existente na sociedade. Assim, Mouffe (2000) propõe a apreensão do político como algo fundamental na constituição de um modelo verdadeiramente democrático, que teria a questão do poder em seu próprio centro. Na perspectiva da autora, a objetividade constituída sob a lógica pública do consenso e da racionalidade configuraria uma estrutura de poder vigente a que a autora trata como a noção de hegemonia. A compreensão de que ordens sociais teriam uma natureza hegemônica e, portanto, objetividade e imparcialidade 
na determinação dos princípios de justiça é uma forma de ocultação do poder no tratamento preferencial a determinadas trajetórias e condições sociais na estruturação da lógica própria das dinâmicas de atribuição de reconhecimento político e, mais além, do que é a política. A proposta, portanto, que Mouffe apresenta, é a de um pluralismo agonístico, que é um pluralismo que compreende a organicidade da organização da sociedade e não nega a existência do conflito na sociedade, de acordo com o qual suas instituições deveriam prover um espaço onde as pessoas e suas divergências morais e políticas pudessem ser expressas a partir do conflito (Mouffe, 2006, p. 30). 0 pluralismo agonístico, assim, é compreendido na ideia de que não é necessário eliminar as paixões da esfera do público - ou seus potenciais conflitivos - mas, sim, tornar possível um consenso mobilizando as paixões e a conflituosidade decorrida das diferenças e dissensos em direção ao ideal democrático.

Ao contrário da sugestão endossada por Rawls, de que apenas a imparcialidade respeita a diferença e levaria a sério o pluralismo, na medida em que se torna possível, no campo abstrato do recurso filosófico rawlsiano da posição original, perceber igualmente a todos e todas, conforme descrito anteriormente, Young (1990) propõe que pretender a imparcialidade é negar a diferença, na mesma direção para a qual aponta Mouffe. Ao acreditar em um ideal de ética moderna que estabelece que a imparcialidade é o marco da razão moral, pauta-se ideias por um ponto de vista externo; ponto de vista que nega a particularidade, elimina a heterogeneidade e reduz a pluralidade à subjetividade (Young 1990, p. 100). A razão moral da imparcialidade teria funções ideológicas de mascarar a perspectiva particular de grupos dominantes que clamam pela imparcialidade. De forma geral, Young argumenta (1990, p. 97) que o ideal de público cívico imparcial da cidadania universal é inadequado, pois seu domínio exclui segmentos identitários associados ao corpo e aos sentimentos, à irracionalidade e, de modo geral, à heterogeneidade, como negros, mulheres e indígenas, contrapondo-se à defesa liberal do universalismo a partir do qual fala Rawls. Nesse sentido, a ideia de que as contingências são ignoradas sob o véu da ignorância não seria imparcial e neutra, mas, sim, fortalecedora de uma condição social hegemônica que se traça a partir de uma trajetória primordialmente dominante - masculina, branca, social e economicamente estabelecida, dentre outras categorias sociais de segmentos dominantes. Desse modo, sob a ordem política democrática a que se desdobrariam todo o conjunto diversificado de grupos sociais e doutrinas morais estabelecidas na cooperação possível, os princípios de Rawls - em sua dimensão 
pública, racional e pretensamente neutra - estariam sujeitos a uma dinâmica social mais ampla, que se valeria não apenas da ingênua aceitabilidade das condições de uma sociedade livre e estável em seu pluralismo cultural, mas de disposições estruturantes de assimetrias existentes entre os grupos em relações de dominação e de opressão consolidadas no processo político e nos espaços mais cotidianos da interação social (Young, 1990), aos quais os princípios rawlsianos parecem não ter chegado para levar justiça aos lugares mais obscuros da sociedade.

\section{Considerações finais}

Embora a teoria rawlsiana tenha grande contribuição como ruptura em um pensamento utilitarista de justiça, sua maior contribuição terá sido, talvez, os caminhos que suas reflexões abriram em direção a um conjunto mais amplo de preocupações relativas à justiça social, não apenas no âmbito em que se faria necessária a igualdade material e de direitos, mas na medida em que o respeito à diversidade e o reconhecimento das diferenças identitárias e culturais também se fizeram cada vez mais presentes dentre os pré-requisitos a uma sociedade mais justa.

Nesse sentido, os fundamentos da teoria rawlsiana, sob o contexto da ordem das sociedades liberais, são objeto importante para uma análise crítica que questione as condições em que direitos, liberdade e justiça são concebidos e idealizados no interior dessas sociedades. Tal análise propõe-se a considerar, sob que constrangimentos e especificidades, princípios ou valores de justiça trariam para a sociedade atual uma justiça mais substantiva, a que se deveria o esforço de ampliar e questionar os elementos necessários para tanto. A teoria de justiça de Rawls oferece um vasto campo de trabalho de crítica e de produção de análises como a de que se vale este trabalho. No longo caminho de que se valem as contribuições empenhadas na justiça das sociedades contemporâneas, o trabalho de Rawls abriu, com suas contribuições e por meio os debates que se seguiram a seus trabalhos, a percepção de que a ordem social desigual está sustentada não apenas pela desigualdade material ou de direitos e oportunidades, mas por vários aspectos também sob os quais a injustiça resguarda-se, como dinâmica do poder, como sob o plano simbólico (Young, 1990) ou como sob as condições de constituição das trajetórias sociais e sob o potencial de manifestação e de exercício de direitos dos vários grupos - muitas vezes hierarquicamente situados - em sociedade. 
Mais uma vez, o trabalho de Rawls mostra-se útil em abrir para outras possibilidades e inovações na constituição de novas formas de pensar a justiça e a dinâmica de uma sociedade justa, não apenas pela justiça em si, mas pelo resgate também da crítica da própria constituição social vigente. Neste âmbito, obstáculos impostos estabelecem ainda sob o potencial de reconhecimento atribuído a determinados segmentos sociais na manifestação de suas necessidades e de sua própria identidade - em suas disputas por reconhecimento político em suas formas de vida e de expressão na esfera pública (HoNNETH, 2003; FRASER, 1997), assim como a dinâmica dessas sociedades tão culturalmente diversificadas permanecem ainda sutilmente impermeáveis e silenciosas à sua própria desigualdade e às relações de poder constituintes de ordens injustas. Para uma análise crítica das condições da sociedade atual, parece ser necessário pensar a respeito do que viria ser o conceito de justiça. Por isso, talvez, os trabalhos de John Rawls ainda se valham de mais interlocuções e resgates para o futuro.

\section{Referências}

Avritzer, L. (2000). “Teoria democrática e deliberação pública”. Lua Nova, n. 50, p. 25-46.

Cohen, J. L.; Arato, A. (1997). Civil society and political theory. Cambridge, MIT Press.

DAHL, R. (2005). Poliarquia: participação e oposição. São Paulo, EduSP.

Durkheim, E. (1978). A divisão do trabalho social. Lisboa, Presença.

FRASER, N. (1997). Justice interruptus: critical reflections on the "postsocialist" condition. New York, Routledge.

; Honneth, A. (2003). Redistribution or recognition? A political-philosophical exchange. London, Verso.

Habermas, J. (2004). A inclusão do outro: estudos e teoria política. 2a edição. São Paulo, Loyola.

Honneth, A. (2003). Luta por reconhecimento: a gramática moral dos conflitos sociais. São Paulo, Ed. 34.

Kelsen, H. (1990). Teoria geral do Direito e do Estado. São Paulo, Martins Fontes.

Mouffe, C. (2000). The democratic paradox. London, Verso.

Mouffe, C. (2006). On the political. New York, Routledge. 
MoufFe, C; LAClAU, E. (1985). Hegemony and socialist strategy: towards a radical democracy politics. London, Verso.

OKIN, S. M. (1989). Justice, gender and the family. New York, Basic Books. (2008). "Gênero, o público e o privado". Estudos Feministas, Florianópolis, 16(2): 440 .

RawLS, J. (1996). Political liberalism. New York, Columbia Press. . (1999). A theory of justice. Cambridge, Belknap. . (2008). Uma teoria da justiça. 3ª edição. São Paulo, Martins Fontes.

Schumpeter, J. (1961). Capitalismo, socialismo e democracia. Rio de Janeiro, Fundo de Cultura.

YounG, I. M. (1990). Justice and the politics of difference. New Jersey, Princeton University Press.

Recebido em outubro/2011

Aprovado em março/2012 